\title{
Effect of incorporating potato dietary fibre to wheat dough on the quality of baked rolls
}

\author{
Michaela Lauková, Zlatica Kohajdová, Jolana Karovičová \\ Institute of Food Science and Nutrition, Faculty of Chemical and Food Technology, \\ Slovak University of Technology, Radlinského 9, 81237 Bratislava, Slovak Republic \\ michaela.laukova@stuba.sk
}

\begin{abstract}
The effect of incorporation of commercial potato dietary fibre at different levels (1, 3, 5 and $10 \%)$ on wheat flour dough rheology, qualitative and sensory properties of baked rolls was evaluated. Potato dietary fibre exhibits good hydration properties (water holding, water retention and swelling capacity). Its addition into wheat dough increased water absorption, prolonged dough stability and dough development time. Also, it was found that the potato fibre incorporation to wheat rolls negatively affects both volume and specific volume, and cambering of baked rolls. Sensory evaluation showed that rolls with the addition of potato dietary fibre at levels 1 and $3 \%$ had high overall acceptability.
\end{abstract}

Keywords: dietary fibre, potato, rheology, dough

\section{Introduction}

The health benefits now known to be associated with dietary fibre include better control of blood glucose and cholesterol levels, protection against cardiovascular diseases, regulation of intestinal function, promotion of gut health and protection against colon cancer. The true intake of dietary fibre in most European countries is lower than the average daily intake of $30 \mathrm{~g}$ recommended in the 2009 European nutrition and health report (Martínez et al., 2014).

Dietary fibres are not only desirable for their nutritional properties, but also for their functional and technological properties, and because of those they can also be used to upgrade agricultural products and by-products for the use as food ingredients (Figuerola et al., 2005). Most commonly, dietary fibres are incorporated into bakery products to prolong freshness, thanks to their capacity to retain water, thereby reducing economic losses. Fibres can modify bread loaf volume, its springiness, the softness of the bread crumb and the firmness of the loaf. As a rule, the incorporation of fibres in bread reduces loaf volume and increases firmness, but the extent of the modification depends on the fibre source (Elleuch ez al., 2011). Plant fibres show some functional properties, such as water-holding capacity, swelling capacity, viscosity or gel formation, bile acid binding capacity, and cation-exchange capacity, which have been more useful for understanding the physiological effect of dietary fibre than the chemical composition alone. These properties are related to the porous matrix structure formed by polysaccharide chains which can hold large amounts of water through hydrogen bonds (Figuerola et al., 2005).
Potatoes are one of the most commonly consumed vegetables throughout the world. Potatoes mainly contain carbohydrates, especially starch, vitamins, minerals and phytochemicals, such as carotenoids and natural phenols (Mirabela et al., 2014). The huge amounts of potato pulp and potato peel that arise from industrial processing of flour and several other potato products may serve as an ingredient in wheat bread. A major reason for this is that bread dough rich in fibre with a high extent of hydration may result in increased lubrication between fibre and other ingredients. The high hydration is due to a high content of cellulose, hemicellulose and lignin in these materials (Kaack et al., 2006).

The purpose of this study was to evaluate the chemical composition and some hydration properties of commercial potato dietary fibre (PDF), and to use it as a flour substituent in baked rolls. The sensory evaluation of final products was also performed.

\section{Material and methods}

\section{Materials}

Potato dietary fibre (PDF) Fibra was obtained from Paleta, s.r.o., Lipnice, Czech Republic, fine wheat flour (WF) T 650 was the product of Penam, Nitra, Slovakia, and other ingredients were purchased in local market.

\section{Chemical analysis}

Moisture, fat, protein and ash contents were determined by modified methods of Fernández-Ginés et al. (2004). Total dietary fibre (TDF) content was measured according to the method of SunWaterhouse et al. (2010). 


\section{Hydration properties}

Water holding capacity (WHC), water retention capacity (WRC) and swelling capacity (SC) were measured according to the method of Raghavendra et al. (2004).

\section{Blended flours preparation}

Blends of $0 \%$ (control), $1 \%, 3 \%, 5 \%$ and $10 \%$ were prepared by replacement of fine wheat flour with commercial PDF.

\section{Rheological properties}

The effect of PDF on dough rheology was determined using Farinograph (Brabender, Duisburg, Germany) according to the method ISO 5530-1:2013. The parameters measured were water absorption (WA), dough stability (DS) and dough development time (DDT).

\section{Rolls preparation}

The wheat rolls and wheat rolls supplemented with PDF were prepared using a recipe according to Kohajdová and Karovičová (2007).

\section{Physical parameters of baked rolls}

The loaf quality was evaluated after cooling for $2 \mathrm{~h}$. Loaf volume $\left(\mathrm{cm}^{3}\right)$ was measured by the millet seeds displacement method (Kohajdová and Karovičová, 2007). Specific volume ( $\mathrm{cm}^{3}$ per $100 \mathrm{~g}$ of loaf) was calculated by dividing the values of volume by weight (Sowbhagya et al., 2015). Cambering of baked rolls was calculated as a ratio of loaf height and width (Kohajdová et al., 2013).

\section{Sensory evaluation}

Sensory evaluation of baked rolls was assessed in descriptors of quality by five-point hedonic scale according to method described by Kohajdová et al. (2013). The evaluated descriptors were: the shape of product, crust colour, crust thickness/ hardness, crust/crumb odour and taste, crumb: elasticity, porosity, colour, resistance to bite, and adhesiveness to palate upon longer chewing. The overall acceptability of rolls was determined using $100 \mathrm{~mm}$ graphical non-structured line with the description of extreme points (minimal or maximal intensity, from 0 to $100 \%$ ) (Kohajdová et al., 2013).

\section{Statistical analysis}

All analyses were carried out in triplicate and the average values were calculated. The results were expressed as mean \pm standard deviation. One way analysis of variance and Fisher's least significant differences procedure were applied to the data to establish the significance of the differences between the samples at the level of $\mathrm{p}=0.05$. Statgraphic Plus, Version 3.1 (Statistical Graphic Corporation, Princeton, NY, USA) was used as the statistical analysis software.

\section{Results and discussion}

The chemical composition of fine WF and PDF is shown in Table 1. It was observed that the TDF content in PDF was $71.05 \%$ which is higher than that reported by Kaack and Pedersen (2005), Ajila et al. (2010), Chau et al. (2004) and Prokopov et al. (2015) in potato pulp (58.9\%), mango peel powder (51.2\%), carrot pomace (63.5) and cabbage leaf powder $(61.43 \%)$. Other PDF traits were both low fat content $(0.16 \%)$ and high ash level (1.48 \%).

Tab. 1. Chemical composition of WF and PDF.

\begin{tabular}{lrr}
\hline & \multicolumn{1}{c}{ WF } & \multicolumn{1}{c}{ PDF } \\
\hline TDF (\%) & $1.54 \pm 0.05$ & $71.05 \pm 0.02$ \\
Moisture (\%) & $10.72 \pm 0.25$ & $10.26 \pm 0.09$ \\
Ash (\%) & $0.40 \pm 0.02$ & $1.48 \pm 0.03$ \\
Proteins (\%) & $10.72 \pm 0.22$ & $6.33 \pm 0.20$ \\
Fat (\%) & $1.35 \pm 0.03$ & $0.16 \pm 0.01$ \\
\hline
\end{tabular}

The technological interest and physiological effects of dietary fibre are related to their functional properties. The hydration properties of dietary fibres determine their optimal usage levels in foods because a desirable texture should be retained (Yaich et al., 2015). The hydration properties of PDF are presented in Table 2. The WHC determined by centrifugation method represents all three types of waters (water bound to the hydrophilic polysaccharides, held within the fibre matrix, trapped within the cell-wall lumen) associated with the fibres (López-Marcos et al., 2015). It was observed that PDF showed higher WHC (7.59 g. $\left.\mathrm{g}^{-1}\right)$ than that reported in sugar beet fibre, pea hull fibre and pea cell wall fibre (Collar et al., 2007). It was also observed that PDF exhibited higher WRC $\left(5.67 \mathrm{~g} \cdot \mathrm{g}^{-1}\right)$ than that described

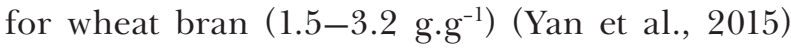
and qingke (hull-less barley) (4.73 g.g $\mathrm{g}^{-1}$ ) (Du et al., 2014) but lower than was reported for carrot peels (12.40-19.63 g.g ${ }^{-1}$ ) (Chantaro et al., 2008) and cherry fibre (7.9-9.5 g.g ${ }^{-1}$ ) (Basanta et al., 2014). These parameters are interesting because they can be associated with the amount of water retained by the fibre, for example, during kneading the dough (de Escalada Pla et al., 2007). The PDF was also characterised with high SC $\left(10.77 \mathrm{~cm}^{3} \cdot \mathrm{g}^{-1}\right)$. Similar values for SC were described by Kohajdová et al. (2012) in carrot pomace powder $\left(10.48 \mathrm{~cm}^{3} \cdot \mathrm{g}^{-1}\right)$. 
Tab. 2. Hydration properties of PDF and WF.

\begin{tabular}{lcr}
\hline & WF & PDF \\
\hline SC $\left(\mathbf{c m}^{3} \cdot \mathbf{g}^{-1}\right)$ & $2.10 \pm 0.01$ & $10.77 \pm 0.02$ \\
WHC $\left(\mathbf{g} \cdot \mathbf{g}^{-1}\right)$ & $1.20 \pm 0.06$ & $7.59 \pm 0.01$ \\
WRC $\left(\mathbf{g} \cdot \mathbf{g}^{-1}\right)$ & $1.45 \pm 0.04$ & $5.67 \pm 0.08$ \\
\hline
\end{tabular}

WF - wheat flour, PDF - potato dietary fibre, SC - swelling capacity, WHC - water holding capacity, WRC - water retention capacity.

Tab. 3. Effect of addition different levels of PDF on dough rheological parameters.

\begin{tabular}{cccc}
\hline & WA (\%) & DDT (min) & DS (min) \\
\hline control & $61.07 \pm 0.32$ & $6.31 \pm 0.19$ & $6.39 \pm 0.29$ \\
$\mathbf{1} \%$ PDF & $63.73 \pm 1.44$ & $8.33 \pm 0.29^{*}$ & $7.83 \pm 0.29^{*}$ \\
$\mathbf{3} \%$ PDF & $70.30 \pm 1.04^{*}$ & $10.50 \pm 0.50^{*}$ & $8.17 \pm 0.29^{*}$ \\
$\mathbf{5} \%$ PDF & $72.87 \pm 0.31^{*}$ & $10.83 \pm 0.29^{*}$ & $8.96 \pm 0.15^{*}$ \\
$\mathbf{1 0} \%$ PDF & $79.35 \pm 2.51^{*}$ & $11.73 \pm 0.32^{*}$ & $12.00 \pm 0.00^{*}$ \\
\hline
\end{tabular}

*denotes a statistically significant difference at $\mathrm{p}=0.05$ level, PDF - potato dietary fibre, WA - water absorption, DDT - dough development time, DS - dough stability.

Rheological properties of dough have an important effect on baking characteristics. To predict the final products quality, it is necessary to have a good knowledge about these properties and their related parameters (Mirsaeedghazi et al., 2008). The effect of PDF addition on dough rheology properties is presented in Table 3. WA is the amount of water required to develop dough to the point of greatest torque when, for wheat flour, the gluten would have been fully developed (Bakare et al., 2015). It was observed that the addition of high levels of PDF (3-10 \%) significantly increased WA. This effect is likely caused by the great number of hydroxyl groups existing in the fibre structure, which allow more water interactions through hydrogen bonding (Wang et al., 2002). Similar effects on WA were reported by Bojňanská et al. (2014) and Rodriguez-Sandoval et al. (2012) after addition of potato fibre and potato flour to wheat dough.
It can be also noticed that DDT was markedly prolonged with increasing levels of PDF from $6.31 \mathrm{~min}$ (control) to $11.73 \mathrm{~min}$ (dough with $10 \%$ PDF). This effect could be attributed to a fibre gluten interaction, which prevents protein hydration. However, this effect could be also related to some sort of competition for water between fibre and the other flour components, which leads to a progressive dehydration of dough creating the impression of dough strengthening (Gómez et al., 2011). The same effect on DDT was observed by Kučerová et al. (2013), Borchani et al. (2011) and Mohammed et al. (2012), who substituted wheat flour by potato fibre, date flesh and chickpea flour, respectively.

Dough stability (DS) indicates how much tolerance the flour has to over- or under-mixing (Bakare et al., 2015). It was found that the incorporation of PDF significantly prolonged DS from $6.39 \mathrm{~min}$ (control) to $12.00 \mathrm{~min}$ (10\% PDF). These observations were consistent with those of Kohajdová et al. (2012) after addition of carrot pomace powder to wheat flour dough.

The physical parameters of baked wheat rolls with addition of PDF at different levels are shown in Table 4. Loaf volume is used as a criterion to measure the quality of fresh bread in the industrial quality control, and by consumers. Specific volume of loaves of bread provides a uniform basis for comparing results of various studies. It is an indication of the gluten content of the bread but other constituents such as starch and fibre also contribute to the specific volume of bread (Bakare et al., 2015). It was found that the incorporation of PDF at levels of $3-10 \%$ decreased both volume and specific volume of baked rolls. These results were in agreement with those obtained by Kohajdová et al. (2012), Sangnark et al. (2004) and Mohammed et al., (2012) after addition of carrot pomace powder, bagasse and chickpea to baked rolls or bread, respectively.

The decrease in the loaf volume could be caused by the dilution of gluten, and also could result from the interaction between gluten and fibre material. The specific volume decreased due to fibre addition, which have already been reported (Anil et al., 2007).

Tab. 4. Effect of PDF addition on physical parameters and overall acceptance of wheat rolls.

\begin{tabular}{ccccc}
\hline & $\begin{array}{c}\text { Volume } \\
\left(\mathbf{c m}^{3}\right)\end{array}$ & $\begin{array}{c}\text { Specific volume } \\
\left(\mathbf{c m}^{3} \cdot \mathbf{g}^{-1}\right)\end{array}$ & Cambering & Overall acceptability (\%) \\
\hline control & $285.33 \pm 4.16$ & $3.3099 \pm 0.68$ & $0.59 \pm 0.01$ & $99.31 \pm 0.05$ \\
$\mathbf{1} \% \mathbf{P D F}$ & $283.00 \pm 6.93$ & $3.2060 \pm 0.32$ & $0.58 \pm 0.01$ & $97.57 \pm 0.12$ \\
$\mathbf{3} \% \mathbf{P D F}$ & $244.67 \pm 6.43^{*}$ & $2.8230 \pm 0.51^{*}$ & $0.47 \pm 0.02^{*}$ & $96.85 \pm 0.08$ \\
$\mathbf{5} \% \mathbf{P D F}$ & $186.00 \pm 6.93^{*}$ & $2,1754 \pm 0.37^{*}$ & $0.46 \pm 0.01^{*}$ & $91.46 \pm 0.15^{*}$ \\
$\mathbf{1 0} \% \mathbf{P D F}$ & $170.36 \pm 4.28^{*}$ & $2.0281 \pm 0.43^{*}$ & $0.43 \pm 0.01^{*}$ & $89.52 \pm 0.06^{*}$ \\
\hline
\end{tabular}

*denotes a statistically significant difference at $\mathrm{p}=0.05$ level. 


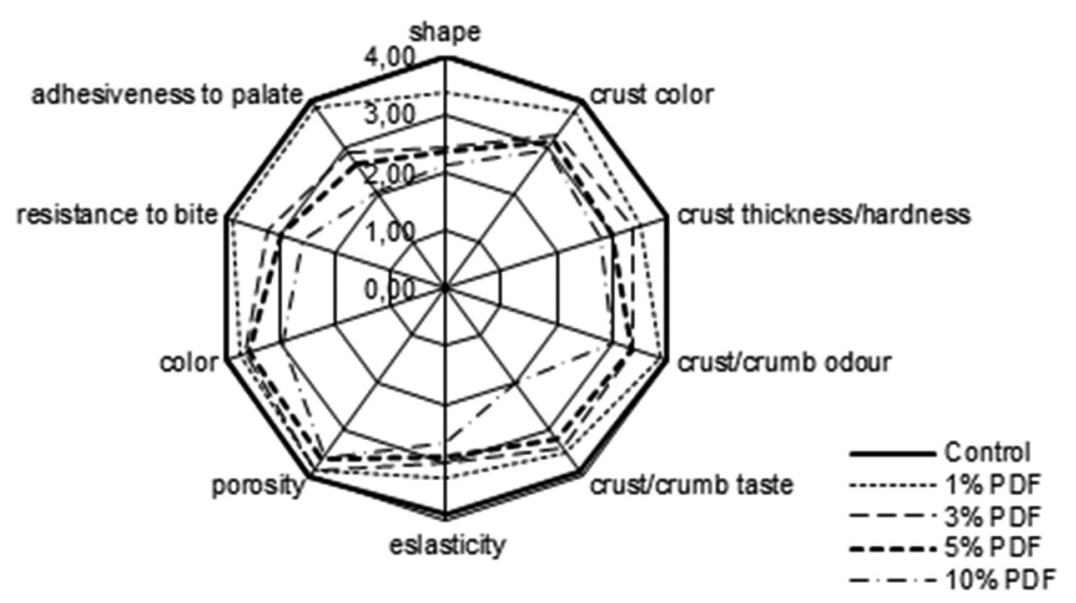

Fig. 1. Sensory parameters of PDF-enriched wheat rolls.

It was observed that the incorporation of PDF to wheat rolls negatively affected the cambering of baked products. It was stated that cambering values under 0.50 are not satisfactory (Kohajdová et al., 2012). This criterion was not fulfilled in products with the addition of PDF at level 3-10\%.

The effect of PDF on sensory parameters of baked rolls is presented in Figure 1. Products with addition of PDF at level 3, 5 and $10 \%$ had significantly darker crust colour. The similar effect was reported by Kohajdová et al. (2012) after addition of carrot pomace powder. The PDF enrichment of wheat rolls also affected the shape, adhesiveness to palate and resistance to bite of final products. It was also shown (Table 4) that no significant differences in overall acceptance were found between control rolls and rolls incorporated with 1 and $3 \%$ of PDF.

\section{Conclusion}

Bread contains a plethora of important nutritional components which exert a positive influence on the human health. In spite of this, the addition of fibre into bread and wheat products is still very important (Kučerová et al., 2013). Peels are the major by-product of potato processing industries and contain the same amount of valuable compounds as edible vegetable (Mirabela et al., 2014). During this study, it was found that PDF can be considered as good source of dietary fibre for bakery products due to high content of TDF (71.05\%). Moreover, it was found that PDF was characteristic by suitable hydration properties (WHC, WRC and SC), which indicates the potential of PDF to be used as a functional ingredient to avoid syneresis and to modify the viscosity and texture of formulated products (Kohajdová et al., 2013). Results show that PDF modified rheological properties of wheat dough (increased WA and prolonged DDT and DS). Fur- thermore, it was also observed that the addition of PDF significantly decreased physical parameters (volume, specific volume and cambering) and overall acceptability of wheat rolls.

Acknowledgments

This work was supported by courtesy of Slovak Grant Agency (VEGA 1/0487/16, 1/0453/13).

\section{References}

Ajila CM, Aalami M, Leelavathi K, Prasada Rao UJS (2010) Innov. Food Sci. Eng. 11: 219-224.

Anil M (2007) J Food Eng 80(1): 61-67.

Basanta MF, de Escalada Pla MF, Raffo MD, Stortz CA, Rojas (2014) J Food Eng 126: 149-155.

Bakare A, Osundahunsi F, Olusanya JO, (2015) Food Sci. Nutr (in press) doi: 10.1002/fsn3.321.

Bojňanská T, Tokár M, Frančáková H (2014) Potr. 8 (1): 161-166.

Borchani Ch, Masmoudi M, Besbes S, Attia H, Deroanne C, Blecker Ch (2011) J. Texture stud. 42 (4): 300-308.

Collar C, Bollaín C, Rosell CM (2007) Food Sci. Technol. Int. 13(2): 99-107.

de Escalada Pla MF, Ponce NM, Stortz CA, Gerschenson LN, Rojas AM (2007) LWT - Food Sci. Technol. 40(7): $1176-1185$

Du B, Zhu F, Xu B (2014) Bioact. Carbohydr. Dietary Fibre 170-175.

Elleuch M, Bedigian D, Roiseux O, Besbes S, Blecker Ch, Attia H (2011) Food Chem 124: 411-421.

Figuerola F, Hurtado ML, Estevéz AM, Chiffelle I, Asenjo F (2005) Food Chem 91: 395-401.

Gómez M, Jiménez S, Ruiz E, Oliete B (2011) LWT - Food Sci. Technol. 44(10): 2231-2237.

Chantaro P, Devahastin S, Chiewchan N (2008) LWT - Food Sci. Technol. 41(10): 1987-1994.

Chau CH-F, Chen Ch-H, Lee M-H, (2004) Lebensm. Wiss. u. Technol. 37: 155-160.

ISO 5530-1:2013. Wheat flour - Physical characteristic of doughs - Part 1: Determination of water absorption and rheological properties using a farinograph. 
Kaack K, Pedersen L (2005) Eur. Food Res. Technol. 221: 313-319.

Kaack K, Pedersen L, Laerke HN, Meyer A (2006) Eur. Food Res. Technol. 224: 199-207.

Kučerová J, Šottníková V, Nemodová Š (2013) Czech J. Food Sci. 31(4): 340-346.

Kohajdová Z, Karovičová J (2007) Żywn. Nauka Technol. Jakość 53(4): 36-45.

Kohajdová Z, Karovičová J, Jurasová M (2012) Acta Sci. Pol. Technol. Aliment 11(4): 381-387.

Kohajdová Z, Karovičová J, Jurasová M (2013) Acta Aliment. 42(1): 91-101.

López-Marcos MC, Bailina C, Viuda-Martos M, PérezAlvarez JA, Fernández-López J (2015) Food Bioprocess Technol. 8: 2400-2408.

Martínez MM, Díaz Á, Gómez M, (2014) J. Food Eng. 142:49-56.

Mirabela N, Castellani V, Sala S (2014) J. Clean. Prod. 65: 28-41.

Mirsaeedghazi H, Emam-Djomeh Z, Mousavi SMA (2008) Int. J. Agri. Biol. 10: 112-119.
Mohammed I, Ahmed AR, Senge B (2012) Ind. Crops Prod. 36: 196-20.

Prokopov T, Goranova Z, Baeva M, Slavov A, Galanakis ChM (2015) Int. agrophys. 29(4): 1-8.

Rodriguez-Sandoval E, Sandoval G, Cortes-Rodríguez M (2012) Braz. J. Chem. Eng. 29(3): 503-510.

Raghavendra SN, Rastogi NK, Raghavarao KSN, Tharanathan RN (2004) Eur. Food Res. Technol. 218: 563-566.

Sangnark A, Noomhorm A, (2004) Lebensm. Wiss. u. Technol. 37: 697-704.

Sowbhagya HB, Suomya C, Indrani D, Srinivas P (2015) J. Food Sci. Technol. 52(11): 7218-7226.

Sun-Waterhouse D, Teoh A, Massarotto C, Wibisono R, Wadhwa S (2010) Food Chem. 119: 1369-1379.

Yan X, Ye R, Chen Y (2015) Food Chem. 180: 106-115.

Yaich H, Garna H, Bchir B, Besbes S, Paquot M, Richel A, Blecker CH, Attia H (2015) Algal Res. 9: 65-73. 